\title{
Design of an Impact Absorbing Composite Panel from Denim Wastes and Acrylated Epoxidized Soybean Oil based Epoxy Resins
}

\author{
Janset OZTEMUR (D) 0000-0002-7727-9172 \\ Hande SEZGIN (D) 0000-0002-2671-2175 \\ Ipek YALÇIN-ENIS (DD 0000-0002-7215-3546
}

Istanbul Technical University / Textile Technologies and Design Faculty/Textile Engineering Department/Istanbul, Turkey

Corresponding Author: Janset Oztemur, oztemurj@itu.edu.tr

\begin{abstract}
The focus of this work is to make a significant contribution to solid waste management by designing impact-absorbing bio-composite panels using bio-resin and denim wastes. In this context, composite panels are produced by vacuum infusion technique using both epoxy and acrylated epoxidized soybean oil (AESO) based hybrid resins while denim wastes are utilized as reinforcement materials in fiber and fabric forms. Both physical (fiber density and fiber weight ratio) and mechanical analyses (drop-weight impact resistance and dynamic mechanical analysis (DMA)) of the composites are performed. The outcomes of the study prove that the increase in the AESO ratio of the resin system improves the ductility of the composite and consequently the impact resistance. On the other hand, dynamic mechanical analysis results indicate that the AESO plug-in reduces the storage module and increases the damping factor.
\end{abstract}

\section{INTRODUCTION}

The textile industry is a significant threat to the environment, especially due to the processing of raw materials, fabric preparation and finishing processes, as well as post-consumer waste, and it accounts for $5 \%$ of the world's pollutants [1]. It is estimated that the waste volume, which was only 92 million tons of global fashion waste in 2015, will increase to 148 million tons in 2030. In addition, a much larger amount is encountered when upholstery, bedding, mattresses, packaging, rugs and carpets and automotive interiors are added to this volume [2]. However, it is a fact that only $15 \%$ of the textile wastes is recycled and the rest is buried in landfills [3-4]. This situation encourages the search for alternative products that can turn this risky waste group into an advantage as a raw material, and bio-composites have an important share at this point.
Bio-composites generally consist of petroleum-based matrix and natural reinforcement materials [5]. Biocomposites containing natural fibers have become increasingly important considering the difficulties in plastic disposal and the overuse of petroleum resources [6]. The use of recycled natural fiber reinforcement takes this issue one step further. For instance, denim fabrics are particularly harmful to the environment in both pre-consumer and postconsumer stages, and unfortunately, most of the denim waste cannot be recycled. For this reason, non-recyclable denims, which have strong and stiff structure, can be used in composite constructions to minimize environmental impact [7-8]. There are many other bio-composite studies of petroleum-based matrix reinforced with different recycled natural fibers in the literature [9-11].

On the other hand, when petroleum-based polymers are used with natural reinforcement in a composite structure,

To cite this article: Öztemur J, Sezgin H, Yalçın-Enis I. 2021. Design of an ımpact absorbing composite panel from denim wastes and acrylated epoxidized soybean oil based epoxy resins. Tekstil ve Konfeksiyon, 31(3), 228-234. 
this composite cannot be said to be completely "bio" since the resins have serious environmental impacts besides their benefits such as availability and low cost [12-13]. Thus, considering the sustainability and environmental concerns, matrix materials as well as reinforcement materials used during composite production becomes crucial. This leads to the emergence of the term "green composites". Green composites can be defined as composite structures in which both the reinforcement and matrix materials are obtained from renewable resources [14].

Although petroleum-based epoxy resin is widely preferred in composite materials due to its low cost, ease of use and high mechanical properties, uncertainties about petroleum resources, prices and environmental effects necessitate reducing the use of epoxy and replacing it with biomaterials [15]. The most common bio-resins used in green composites are vegetable oils such as soybean oil, castor oil, palm oil, linseed oil, and sunflower oil [16]. Among them, acrylated epoxized soybean oil (AESO) which is produced by the epoxidation and acrylization of soybean oil, is commercially available choice and it has benefits such as non-volatile and non-toxic structure. However due to its high viscosity at room temperature and low crosslinking capacity, it is mostly used in hybrid resin systems [17-18].

In the literature, many studies are conducted with composite production including AESO resin and natural fiber reinforcements. In a study conducted by Temmink et al. (2018), it was seen that composites reinforced with fourplied denim fabric, containing bio-epoxy and AESO have very acceptable tensile strength (approximately $50 \mathrm{MPa}$ for bio-epoxy and $20 \mathrm{MPa}$ for AESO) and impact resistance (approximately $25 \mathrm{~kJ} / \mathrm{m}^{2}$ for bio-epoxy and $30 \mathrm{~kJ} / \mathrm{m}^{2}$ for AESO) values in comparison to polyester resin systems that serve alternatives for application areas such as automotive interior parts, furniture, interior construction, and leisure equipment [19]. In a similar way, a research on hybrid biobased composites developed by vacuum infusion technique with reinforcement of woven jute fabric and AESO/epoxy blended matrix was implemented by Ozkur et al (2020). Results indicated that the ascending AESO ratio increased the impact resistance of the material, but when the AESO ratio was more than $30 \mathrm{wt}$. $\%$, the tensile strength of the material decreased, thus 30-50 wt. \% AESO was stated as optimum hybridization ratio with epoxy [5]. The enhanced plasticity with the addition of AESO to the epoxy resin reinforced with natural fiber composites are also studied by Bakar et al [15] and Kocaman and Ahmetli [20].

On the other hand, it is not possible to see studies on recycled natural based textile wastes with AESO in the literature. In this context, in this study, bio-composite structures with improved impact resistance are produced by reinforcing epoxy resin and AESO with waste denim structures in both fabric and fiber web form. Eight different designs are produced via vacuum infusion method by changing the resin type and/or reinforcement form (fiber/fabric). The drop-weight impact resistance and thermo-mechanical properties of the composite samples are evaluated.

\section{MATERIAL AND METHOD}

\subsection{Materials}

Waste denim fabrics utilized in this study are supplied from Calik Denim (Table 1) and used as reinforcement materials in either fabric or fiber web form. Epoxy (F-1564, FIBERMAK) and AESO (Sigma Aldrich) are used as matrix materials while a hardener (F-3486, FIBERMAK) is added to the resin system to initiate the curing process. The properties of the matrix components are listed in Table 2.

\subsection{Method}

\section{Preparation of reinforcement materials}

The waste denim fabrics are shredded two times by rag pulling machine (Balkan Makina, Turkey) for the preparation of fiber webs, and then transferred to the carding machine to obtain smooth surfaces at homogeneous web density. These fiber webs are used either alone or in combination with fabric forms to form sandwich structures. The preparation steps of the reinforcement materials are seen in Figure 1.

Table 1. Physical properties of denim fabric

\begin{tabular}{ll}
\hline Warp yarn type / yarn count & ring spun / Ne 9 \\
\hline Weft yarn type / yarn count & core spun / Ne 10 \\
\hline Fiber type & $98 \%$ cotton $2 \%$ elastane \\
\hline Weave type & $3 / 1$ Twill $(\mathrm{Z})$ \\
\hline Areal density $\left(\mathrm{g} / \mathrm{m}^{2}\right)$ & $289.5 \pm 6.36$ \\
\hline Count of cloth $(\mathrm{ends} / \mathrm{cm} *$ picks $/ \mathrm{cm})$ & $32 * 20$ \\
\hline
\end{tabular}

Table 2. The properties of matrix components

\begin{tabular}{cccc}
\hline & Epoxy & AESO & Hardener \\
\hline Viscosity $\left(\mathbf{2 5}^{\circ} \mathbf{C}\right)(\mathbf{c p s})$ & $1200-1400$ & $18000-32000$ & $10-20$ \\
Density $\left(\mathbf{2 5}^{\circ} \mathbf{C}\right)\left(\mathbf{g} / \mathbf{c m}^{3}\right)$ & 1.15 & 1.40 & 1.00 \\
\hline
\end{tabular}




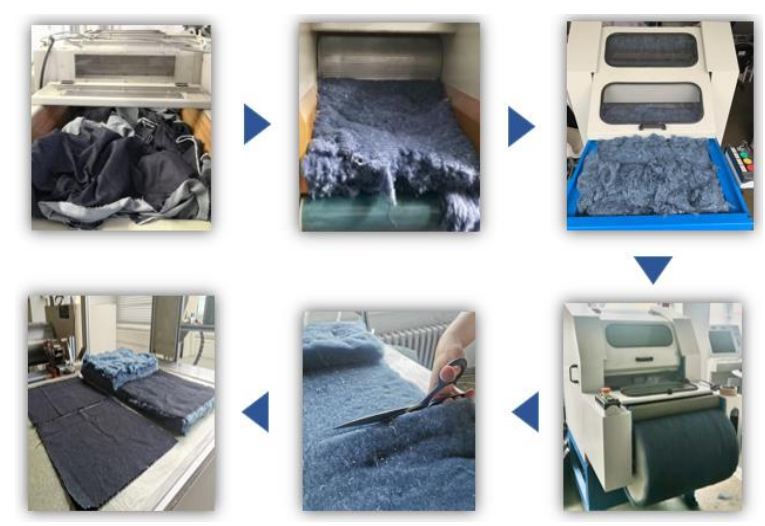

Figure 1. Preparation steps of reinforcement materials

\section{Composite Panel Production}

The composites are produced by the vacuum infusion technique (Figure 2). With this method, the resin is distributed homogeneously to reinforcement material and the excess resin in the composite is vacuumed [21].

Eight different composite samples are produced by varying reinforcement forms and resin systems. Also, the layers of the panels are created by keeping the weights constant. In structures consisting of different layers, the fabric and the fiber layer have the same weight. The details of the composite designs with sample codes are listed in Table 3.

For physical and mechanical analysis, test samples are cut by $\mathrm{CNC}$ milling machine according to the related standards.

\section{Physical Analysis}

Average thicknesses, densities and fiber weight ratios of composite samples are calculated based on the measured weights and dimensions, also results are given with standard deviations (SD).

\section{Mechanical Analysis}

\section{Drop-weight Impact Resistance}

The drop-weight impact resistance analysis is performed via an impact tester (Besmak) with $16 \mathrm{~mm}$ diameter striker according to the ASTM D7136 standard. 59*88mm cut composite samples are subjected to 12 Joule impact energy with a standard hemispherical head. Maximum load, absorbed energy and maximum displacement are measured for five samples from each sample group and average results are given with standard deviations.

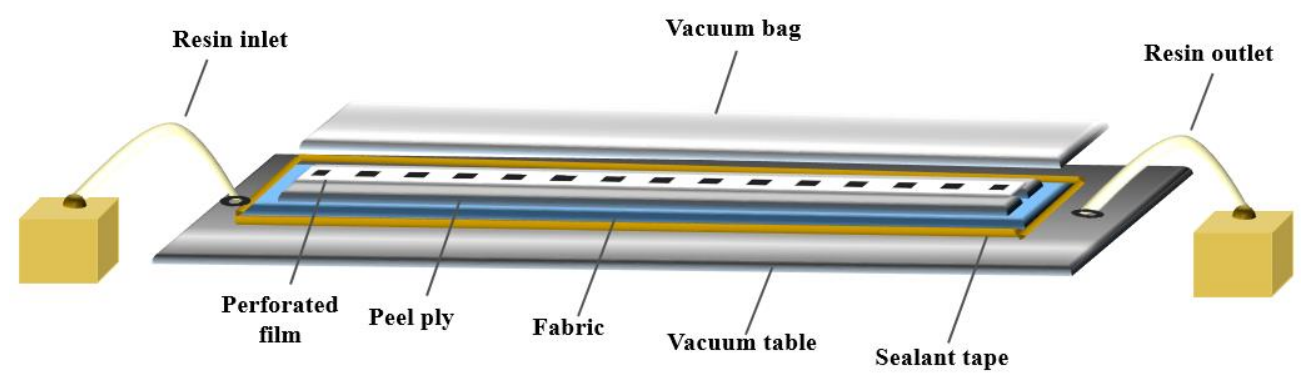

Figure 2. Vacuum infusion set-up.

Table 3. Composite designs

\begin{tabular}{cccc}
\hline Sample Codes & Reinforcement Type & $\begin{array}{c}\text { Resin Weight Ratio } \\
\text { (Epoxy:AESO) }\end{array}$ & $\begin{array}{c}\text { Hardener Weight Ratio } \\
(\%)\end{array}$ \\
\hline DD-30 & Two layers of denim fabric & $(70: 30)$ & 33 \\
DDD-30 & Three layers of denim fabric & $(70: 30)$ & 33 \\
DFD-30 & Fiber web between two layers & $(70: 30)$ & 33 \\
of denim fabric & & 33 \\
FFF-30 & Three layers of fiber web & $(70: 30)$ & 33 \\
DD-0 & Two layers of denim fabric & $(100: 0)$ & 33 \\
DDD-0 & Three layers of denim fabric & $(100: 0)$ & 33 \\
DFD-0 & Fiber web between two layers & $(100: 0)$ & $(100: 0)$ \\
of denim fabric & Three layers of fiber web & & \\
\hline
\end{tabular}




\section{Dynamic Mechanical Analysis}

Dynamic mechanical analysis (DMA) is performed on a DMA testing apparatus (Mettler Toledo, SDTA861) in three-point bending mode by using rectangular samples $(10 * 50 \mathrm{~mm})$ in conformity with ASTM D7028 test standard. Experiments are carried out in the temperature range of 20 ${ }^{\circ} \mathrm{C}$ to $100{ }^{\circ} \mathrm{C}$ with heating rate of $3{ }^{\circ} \mathrm{C} / \mathrm{min}$ with a constant frequency of $10 \mathrm{~Hz}$.

\section{RESULTS AND DISCUSSION}

\subsection{Physical Analysis}

The average thicknesses, densities and fiber weight ratios are listed in Table 4.

It is observed that the average densities of composites containing different resin systems are very similar to each other, and the differences are observed between samples produced with different reinforcement forms such as fabric or fiber webs. For example, DD and DDD samples have almost the same densities with similar fiber weight ratios. Despite the increase in the number of fabric layers, similar values between DD and DDD show that the resins display a homogeneous distribution throughout the fabric and the amount of absorbed resin increases at the same rate due to the increasing number of layers, thus the sample thickness. This can be explained by the advantages of the vacuum infusion technique, which allows production under constant pressure [22].
On the other hand, regardless of resin type, the samples containing fiber web layers (DFD and FFF) have higher densities (1.02-1.03 and 0.95-0.96 g/ $/ \mathrm{cm}^{3}$, respectively) with lower fiber weight ratios (32-35 and 32\%, respectively). This can be clarified by the higher resin absorption due to the loose nature of the fibrous layers compared to denim fabrics, thus allowing the higher amount of resin trapped. In tight structures compared to loose ones, the matrix is more constrained and this leads to various mechanical behavior differences [23]. FFF samples in both resin groups are the thickest samples manufactured under same pressure due to its fluffy fibrous content that results in higher resin absorption levels.

\subsection{Drop-weight Resistance}

The reinforcement material is very effective in defining the final impact properties of composites [24-27]. For this reason, as can be seen in Table 5, as the layers of reinforcement material in the composite structure change, the impact resistance values of the structure differ. DDD has higher maximum load, absorbed energy, and maximum displacement values than DD as a result of the addition of one more fabric layer. Studies in the literature also support that the increment in the number of fabric layers used as reinforcement material increases the impact resistance [28]. In particular, the impact energies absorbed by DDD samples are more than twice of the impact energies absorbed by DD samples.

Table 4. Average thicknesses, densities and fiber weight ratios of the composites

\begin{tabular}{cccc}
\hline Sample Codes & Avg. Thickness \pm SD $(\mathbf{m m})$ & Avg. Density \pm SD $\mathbf{( g / \mathbf { c m } ^ { 3 } )}$ & Avg. Fiber Weight Ratio \pm SD \\
\hline DD-30 & $1.89 \pm 0.05$ & $0.92 \pm 0.03$ & $0.45 \pm 0.01$ \\
DDD-30 & $2.73 \pm 0.22$ & $0.91 \pm 0.07$ & $0.47 \pm 0.00$ \\
DFD-30 & $2.22 \pm 0.12$ & $1.03 \pm 0.02$ & $0.32 \pm 0.01$ \\
FFF-30 & $3.52 \pm 0.19$ & $0.95 \pm 0.09$ & $0.35 \pm 0.01$ \\
DD-0 & $1.85 \pm 0.41$ & $0.98 \pm 0.18$ & $0.45 \pm 0.02$ \\
DDD-0 & $2.79 \pm 0.21$ & $0.97 \pm 0.26$ & $0.44 \pm 0.07$ \\
DFD-0 & $3.49 \pm 0.24$ & $1.02 \pm 1.02$ & $0.32 \pm 0.02$ \\
FFF-0 & $3.79 \pm 0.52$ & $0.96 \pm 0.08$ & $0.32 \pm 0.03$ \\
\hline
\end{tabular}

Table 5. Drop-weight impact resistance test results

\begin{tabular}{cccc}
\hline Sample Codes & Max Load \pm SD $(\mathbf{k N})$ & Absorbed Energy \pm SD (J) & Max Displacement \pm SD (mm) \\
\hline DD-30 & $0.84 \pm 0.06$ & $3.48 \pm 0.33$ & $10.10 \pm 0.02$ \\
DDD-30 & $1.35 \pm 0.10$ & $8.77 \pm 0.52$ & $13.40 \pm 0.17$ \\
DFD-30 & $1.67 \pm 0.05$ & $9.03 \pm 0.46$ & $9.88 \pm 0.44$ \\
FFF-30 & $1.43 \pm 0.11$ & $7.36 \pm 0.67$ & $9.42 \pm 0.92$ \\
DD-0 & $0.83 \pm 0.04$ & $3.50 \pm 0.13$ & $11.10 \pm 0.17$ \\
DDD-0 & $1.22 \pm 0.09$ & $7.31 \pm 0.39$ & $13.40 \pm 0.52$ \\
DFD-0 & $2.15 \pm 0.14$ & $7.95 \pm 0.60$ & $7.41 \pm 0.65$ \\
FFF-0 & $1.63 \pm 0.18$ & $5.20 \pm 0.61$ & $6.11 \pm 0.55$ \\
\hline
\end{tabular}


When the FFF and DFD samples that have similar fiber weight ratios are compared with each other, it is seen that the values of maximum load, absorbed energy and maximum displacement are higher for DFD. It is believed that the use of fabric in both the lower and upper layers creates a layer resistant to the falling object, while the fibrous layer acts as an impact-absorbing layer. In sandwich-type composite structures, the core layer provides time and space for high energy absorption when it exposed to an impact loading [29]. In addition, sandwich structures with stiff surface layers and less rigid core structure exhibit improved properties under mechanical loads [30]. When DDD and DFD samples are compared, it can be said that increased impact resistance is obtained by using a fibrous layer in the middle instead of the fabric layer. This can be explained by the high contribution of the fibrous surface in the middle layer to the absorption of impact energy, as explained above.

Comparing resin systems with each other; by adding $30 \%$ AESO to the epoxy resin, it has been observed that the absorbed impact energy and maximum displacement are improved in almost all samples. Also, the damage patterns on the composite panels can be seen in Figure 3. As can be seen from the images, while very sharp fractures occur in epoxy-based composites, the fractures in samples with AESO added are much softer. In addition, the fact that AESO additive increases the impact resistance is a situation supported by the literature [5].
On the other hand, the maximum load values of the FFF-30 and DFD-30 samples for the AESO resin system (1.43 and $1.67 \mathrm{kN}$, respectively) are lower than the same sample groups for pure epoxy resin systems (for FFF-0 and DFD-0; 1.63 and $2.15 \mathrm{kN}$, respectively). The fiber weight ratios of these samples are relatively lower than that of DDD and DD samples, which means there is more resin in the composite structure. While epoxy resin is preferred for its superior tensile properties in composites, AESO resin is used due to its toughness [31]. For this reason, the increase in the AESO ratio in the increasing resin amount is expected to cause a decrease in the maximum load value.

\subsection{Dynamic Mechanical Analysis}

\section{Storage Modulus}

The storage modulus is an indicator of how much energy the material absorbs and its viscoelastic rigidity [21]. In all sample groups, the storage modulus curves decreases with increasing temperature as seen in Figure 4. At low temperatures, the molecules of the materials are more stable and have a tighter arrangement. However, when the temperature increases from the glassy state to the rubbery state, the mobility of the material improves and its ductile properties increases [32-33]. Figure 4 also shows that AESO-doped structures store less energy in their glassy state compared to epoxy matrix composites and pass through to the rubbery state at relatively lower temperatures due to the lower glass transition temperature $\left(\mathrm{T}_{\mathrm{g}}\right)$ of AESO resin compared to that of epoxy resin.

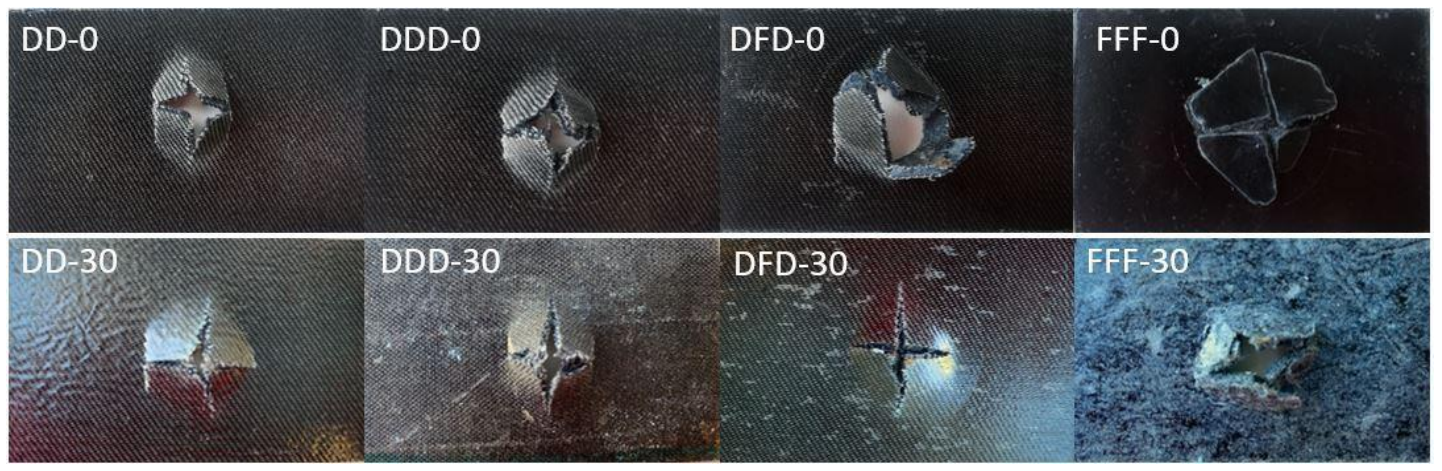

Figure 3. Damage patterns resulting from drop-weight impact test.

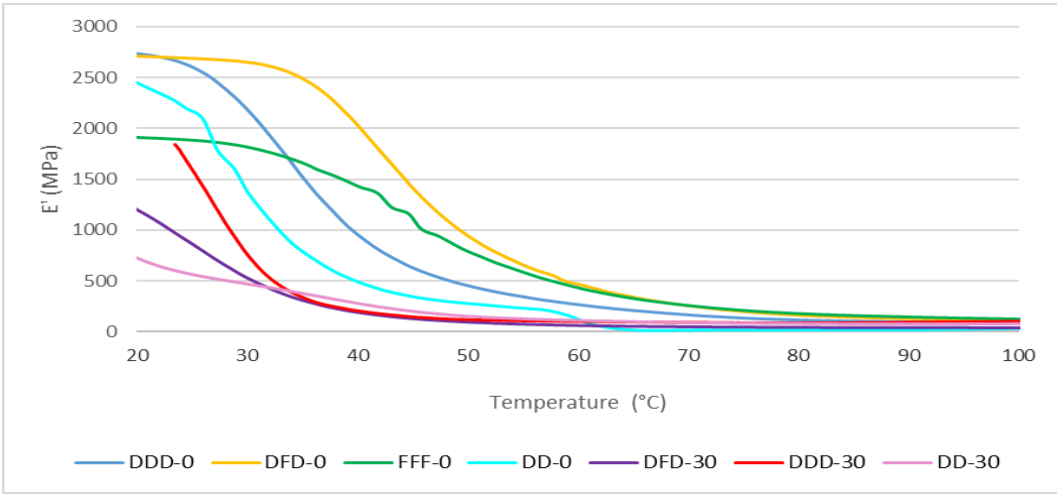

Figure 4. Storage modulus curves of the samples 
Dynamic-mechanical measurements of the FFF-30 composite structure could not be performed due to the dimensional limits (up to $5 \mathrm{~mm}$ in sample thickness is allowed) of the device. Fully fiber reinforced epoxy matrix composite structure (FFF-0) is found to have a lower storage modulus compared to DDD-0 and DFD-0, and this is consistent with drop-weight impact resistance test results. The reason for this behavior, which causes the lower modulus of FFF-0, is the less stiff structure of the fibers in the composite panel and the weaker interaction between the reinforcement and the matrix. Increased interaction between reinforcement and resin decreases the mobility of molecular chains at the interface, improving the composite's rigidity and storage modulus [31]. On the other hand, when examining fabric composite structures with both AESO and epoxy matrix, it is seen that two-layer panels (DD-0 and DD-30) have less storage module compared to three-layer panels.

\section{Damping Factor (Tan delta)}

Tan delta represents the damping characteristic of the structures with viscous or elastic phases and is affected by the matrix-reinforcement interface interaction [34]. Low damping value indicates that reinforcement and matrix materials in composite structures adhere well to each other, while materials with high tan delta value tend to dissipate more energy [32]. In composite panels with epoxy matrix, it is observed that the adhesiveness between matrix and reinforcement is better with the lower level of the tan delta peak (Figure 5). On the other hand, this value varies depending on both the type of resin and its ratio in the composite structure. The damping factor peaks point out to the $T_{g}$ value of the material. After this temperature, the immobility of the structure decreases and the panel begins to turn into a rubbery form. While the $\mathrm{T}_{\mathrm{g}}$ values of epoxy based composites are around $45^{\circ} \mathrm{C}$, it is seen that the $\mathrm{T}_{\mathrm{g}}$ values of AESO/epoxy based composites are around $30^{\circ} \mathrm{C}$. Considering that the $\mathrm{T}_{\mathrm{g}}$ value of AESO resin is around $20^{\circ} \mathrm{C}$ [35], the decrease in $\mathrm{T}_{\mathrm{g}}$ obtained with the addition of AESO is an expected result. The outcomes of the study conducted by Niedermann (2014) also support that the addition of soybean oil resin to aromatic epoxy resins result in a decreased $\mathrm{T}_{\mathrm{g}}$ value [36].

As seen in Figure 5, the $\mathrm{T}_{\mathrm{g}}$ value decreases with the addition of AESO to the structure. However, these structures had wider peaks, indicating a mixture of heterogeneous structures providing a wider temperature range to initiate viscous chain motions [31].

\section{CONCLUSION}

It is thought that this study, which is carried out using waste denim fabrics and bio-resins, will contribute to the solid waste management by serving a greener alternative to traditional composite industry. In the scope of the study, by using different combinations of matrix and reinforcement materials; physical, mechanical and thermo-mechanical properties of the composite samples are investigated. The main results obtained remark that the panels with fiber reinforcement in their structure (FFF-0, FFF-30, DFD-0, and DFD-30) have higher densities with lower fiber weight ratios due to the loose nature of the fibrous structures that allows more resin absorption. In addition, the composites produced with an epoxy:AESO hybrid resin system have higher ductility due to the content of bio-resin and consequently the impact resistance of the composite material increases. On the other hand, regardless of the resin type, the drop-weight impact test results show that three-layer fabric (DDD) and fabric/fiber (DFD) reinforced panels absorb more energy than remaining samples. From the point of dynamic mechanical analysis, the effect of the matrix material is clearly observed. Due to the nature of AESO, the $T_{g}$ value in AESO doped composites is quite lower compared to the other samples. It is also found that DDD-0 and DFD-0 panels with epoxy matrices have the highest storage moduli and relatively low tan delta values.

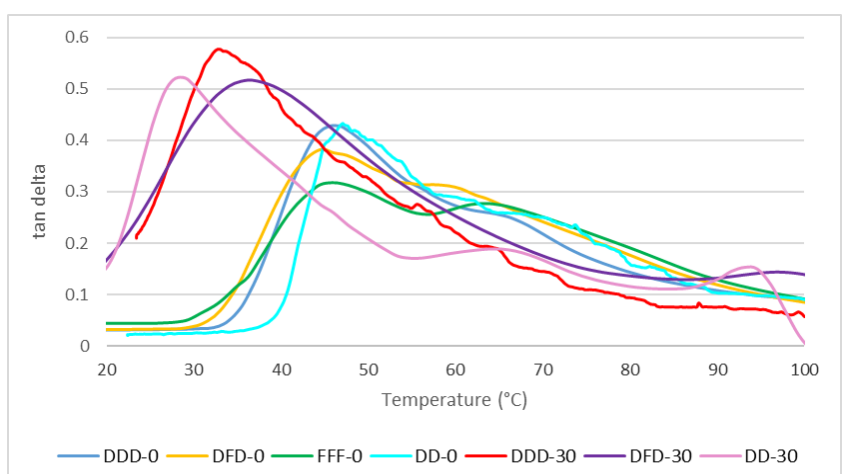

Figure 5. Tan delta curves of the samples

When the results obtained are evaluated holistically, especially AESO-doped fiber/fabric sandwich structured (DFD-30) samples can be used as shock absorbing panels in various end use areas such as construction and automotive, thanks to their improved impact resistance properties. In addition, it can make a significant contribution to solid waste management thanks to the utilization of denim wastes and its bio-resin content.

\section{Acknowledgement}

This study is funded by the Istanbul Technical University Scientific Research Projects under grant no. BAP 40598. The authors also would like to thank Sevgi Aydanur Ceylan and Gokce Sakmar for their kind contribution to this study. 


\section{REFERENCES}

1. Stanescu MD. 2021. State of the art of post-consumer textile waste upcycling to reach the zero waste milestone. Environmental Science and Pollution Research 28, 14253-14270.

2. Echeverria CA, Handoko W, Pahlevani F, Sahajwalla V. 2019 Cascading use of textile waste for the advancement of fibre reinforced composites for building applications. Journal of Cleaner Production 208, 1524-1536.

3. Shirvanimoghaddam K, Motamed B, Ramakrishna S, Naebe M. 2020. Death by waste: Fashion and textile circular economy case. Science of the Total Environment 718, 137317.

4. Wang Y. 2010. Fiber and textile waste utilization. Waste and Biomass Valorization 1(1), 135-143.

5. Ozkur S, Sezgin H, Akay E, Yalcin-Enis I. 2020. Hybrid bio-based composites from blends of epoxy and soybean oil resins reinforced with jute woven fabrics. Materials Research Express 7(1), 15335.

6. Gnaba I, Omrani F, Wang P, Soulat D, Ferreira M, Vroman P, Jaouachi B. 2019. Mechanical behavior of flax/polypropylene commingled nonwoven at dry scale: Influence of process parameters. Textile Research Journal 89(5), 791-800.

7. Haque MS, Sharif A. 2017. Processing and characterization of waste denim fiber reinforced polymer composites. International Journal of Innovative Science and Modern Engineering, 2(4), 24-28.

8. Uncu Ak1 S, Candan C, Uygun Nergis B, Onder N. 2020 Understanding denim recycling: a quantitative study with methodology. In Korlu A (Ed.) Waste in Textile and Leather Sectors. United Kingdom: Intechopen, 1-26.

9. Baccouch W, Ghith A, Yalcin-Enis I, Sezgin H, Miled W, Legrand X, Faten F. 2020. Investigation of the mechanical, thermal, and acoustical behaviors of cotton, polyester, and cotton/polyester nonwoven wastes reinforced epoxy composites. Journal of Industrial Textiles. Advance online publication. [https://doi.org/10.1177/ 1528083720901864]

10. Islam M, Sharif A, Hussain M, Hassan I. 2019. Synergic effect of recycled cotton fabric and wood saw dust reinforced biodegradable polypropylene composites. Bangladesh Journal of Scientific and Industrial Research 54(1), 21-30.

11. Wei B, Xu F, Azhar SW, Li W, Lou L, Liu W, Qiu Y. 2015 Fabrication and property of discarded denim fabric/polypropylene composites. Journal of Industrial Textiles, 44(5), 798-812.

12. Narewska J, Lassila L, Fardim P. 2014. Preparation and characterization of new mouldable cellulose-AESO biocomposites. Cellulose 21(3), 1769-1780.

13. Åkesson D, Skrifvars M, Walkenström P. 2009. Preparation of thermoset composites from natural fibres and acrylate modified soybean oil resins. Journal of Applied Polymer Science 114(4), 2502-2508.

14. Pecas P, Carvalho H, Salman H, Leite M. 2018. Natural fibre composites and their applications: a review. Journal of Composites Science 2(4), 66.

15. Abu Bakar MB, Masri MN, Amini MMH, Thirmizir MMZ, Salim MS. 2018, November. Mechanical, thermal and morphological properties of epoxy resin toughened with epoxidized soybean oil. In Abdullah MMA, Bin Abd. Rahim SZ, Bin Mat Saad MN, Bin Ghazli MF, Ahmad R, Bin Mohd Tahir MF and Binti Jamaludin L. (Eds.), AIP Conference Proceedings, (020277). Ho Chi Minh, Vietnam.

16. Grishchuk S. Karger-Kocsis J. 2011. Hybrid thermosets from vinyl ester resin and acrylated epoxidized soybean oil (AESO). Express Polymer Letters 5(1), 2-11.

17. Wu Y, Li K. 2017. Replacement of styrene with acrylated epoxidized soybean oil in an unsaturated polyester resin from propylene glycol and maleic anhydride. Journal of Applied Polymer Science 134(28), 450456 .

18. Liu W, Fei M, Qiu R. 2017, August. Biocomposites from hemp fibers and acrylated epoxidized soybean oil-based resins. 21st International Conference on Composite Materials, Xi'an, China.
19. Temmink R, Baghaei B, Skrifvars M. 2018. Development of biocomposites from denim waste and thermoset bio-resins for structural applications. Composites Part A: Applied Science and Manufacturing 106, 59-69.

20. Kocaman S, Ahmetli G. 2016. Eco-friendly natural filler based epoxy composites. World Academy of Science, Engineering and Technology International Journal of Chemical, Molecular, Nuclear, Materials and Metallurgical Engineering 10(4), 471-474.

21. Sezgin H, Mishra R, Militky J, Berkalp OB. 2020. Mechanical, thermo-mechanical and thermal characteristics of multi-walled carbon nanotubes-added textile-reinforced composites. Journal of Industrial Textiles 50(5), 692-715.

22. Baccouch W, Ghith A, Yalcin-Enis I, Sezgin H, Miled W, Legrand X, Faten F. 2020. Enhancement of fiber-matrix interface of recycled cotton fibers reinforced epoxy composite for improved mechanical properties. Materials Research Express 7(1), 15340.

23. Liang Y, Wang H, Gu X. 2013. In-plane shear response of unidirectional fiber reinforced and fabric reinforced carbon/epoxy composites. Polymer Testing 32(3), 594-601.

24. Arpitha GR, Sanjay MR, Senthamaraikannan P, Barile C, Yogesha B. 2017. Hybridization effect of sisal/glass/epoxy/filler based woven fabric reinforced composites. Experimental Techniques 41(6), 577-584.

25. Awais H, Nawab Y, Anjang A, Md Akil H, Zainol Abidin MS. 2020. Effect of fabric architecture on the shear and impact properties of natural fibre reinforced composites. Composites Part B: Engineering 195,108069

26. Ramesh M, Palanikumar K, Reddy KH. 2013. Mechanical property evaluation of sisal-jute-glass fiber reinforced polyester composites. Composites Part B: Engineering 48, 1-9.

27. Selver E, Dalfi H, Yousaf Z. 2020. Investigation of the impact and post-impact behaviour of glass and glass/natural fibre hybrid composites made with various stacking sequences: Experimental and theoretical analysis. Journal of Industrial Textiles. Advance online publication. [https://doi.org/10.1177/1528083719900670]

28. Shyr TW, Pan YH. 2003. Impact resistance and damage characteristic of composite laminates. Composite Structures 62(2), 193-203.

29. Lampeas G. 2020. Cellular and Sandwich Materials. In Pantelakis S and Tserpes K. (Eds) Revolutionizing Aircraft Materials and Processes. Cham: Springer, 137-162.

30. Skrifvars M, Dhakal H, Zhang Z, Gentilcore J, Åkesson D. 2019. Study on the mechanical properties of unsaturated polyester sandwich biocomposites composed of uniaxial warp-knitted and non-woven viscose fabrics. Composites Part A: Applied Science and Manufacturing 121, 196-206.

31. Sahoo SK, Mohanty S, Nayak SK. 2017. Mechanical, thermal, and interfacial characterization of randomly oriented short sisal fibers reinforced epoxy composite modified with epoxidized soybean oil. Journal of Natural Fibers 14(3), 357-367.

32. Jabbar A, Militký J, Wiener J, Karahan M. 2016. Static and dynamic mechanical properties of novel treated jute/green epoxy composites. Textile Research Journal 86(9), 960-974.

33. Liu W, Chen T, Fei M, Qiu R, Yu D, Fu T, Qiu J. 2019. Properties of natural fiber-reinforced biobased thermoset biocomposites: Effects of fiber type and resin composition. Composites Part B: Engineering 171, 87-95.

34. Shao B, Fang Y, Chen B, Shen J, Xu S, Ou R, Wang Q. 2020. Statistical distribution of mechanical properties and energy absorption of laminated cotton fabric reinforced epoxy composites. Polymer Composites 41(7), 2829-2840.

35. Fu L, Yang L, Dai C, Zhao C, Ma L. 2010. Thermal and mechanical properties of acrylated epoxidized-soybean oil-based thermosets. Journal of Applied Polymer Science 117(4), 2220-2225.

36. Niedermann P, Szebenyi G, Toldy A. 2014. Effect of epoxidized soybean oil on curing, rheological, mechanical and thermal properties of aromatic and aliphatic epoxy resins. Journal of Polymers and the Environment 22(4), 525-536. 